\title{
Activated Persulfate and Hydrogen Peroxide Treatment of Highly Contaminated Water Matrices: A Comparative Study
}

\author{
Niina Dulova, Eneliis Kattel, and Marina Trapido
}

\begin{abstract}
The efficacy of $\mathrm{Fe}^{2+}$-activated persulfate (PS) and hydrogen peroxide (HP) treatment in total organic load and selected organic pollutants removal from different highly polluted industrial effluents was evaluated and compared. The studied wastewater samples involved a paint production wastewater (S1), phenolic wastewater (S2) and mature landfill leachate (S3). The coagulation proved an effective technique to pre-treat $S 1$, and thus to reduce substantially the amount of chemicals required in the subsequent oxidation step. The Fenton treatment $\left(\mathrm{HP} / \mathrm{Fe}^{2+}\right)$ proved more effective S1 post-treatment technology than the $\mathrm{PS} / \mathrm{Fe}^{2+}$ process and resulted in substantial COD and DOC removal as well as in considerable the $\mathrm{BOD}_{7} / \mathrm{COD}$ ratio increase. In the case of $\mathrm{S2}$ and S3, the application of Fenton process also demonstrated higher total organic load removal efficacy than the $\mathrm{PS} / \mathrm{Fe}^{2+}$ system. Conversely, the $\mathrm{HP} / \mathrm{Fe}^{2+}$ oxidation was characterized by a temperature increase and excessive foam formation. The findings of this study provide valuable information for further full-scale applications of $\mathrm{Fe}^{2+}$-activated $\mathrm{HP}$ and PS based processes for the treatment of highly contaminated wastewater with the most effective concentrations of reagents used.
\end{abstract}

Index Terms-Activated persulfate oxidation, Fenton process, organic contaminants, wastewater treatment.

\section{INTRODUCTION}

The application of hydroxyl radical-based advanced oxidation technologies ( $\mathrm{HO}^{\circ}$-AOTs) proved to be highly effective in degradation of persistent and bio-recalcitrant organic pollutants presented in various industrial effluents. The $\mathrm{HO}^{\circ}$ can be formed by the activation of hydrogen peroxide $\left(\mathrm{HP}, \mathrm{H}_{2} \mathrm{O}_{2}\right)$ and/or $\mathrm{O}_{3}$ by transition metals, semiconductors, ultraviolet (UV)/visible and ultrasound (US) irradiation. The main benefits of HO-AOTs include high reaction rates and non-selective oxidation due to hydroxyl radicals, which result in effective degradation of different pollutants and potential reduction of toxicity in the treated water and wastewater [1]-[7]. Among $\mathrm{HO}^{\circ}$-AOTs, the Fenton process is a widely studied and applied technique for wastewater treatment based on the generation of $\mathrm{HO}^{\circ}$ from $\mathrm{HP}$ activated by $\mathrm{Fe}^{2+}$ at preferably acidic $\mathrm{pH} \sim 3$ [6], [8]-[10]. The commonly accepted mechanism of the Fenton process consists of the sequence of reactions, where $\mathrm{HO}^{\circ}$ are produced through Eq. (1) and the activator is regenerated via Eq. (2), or from reaction of $\mathrm{Fe}^{3+}$ with organic radicals [2], [3]:

Manuscript received February 5, 2020; revised October 15, 2020.

The authors are with Tallinn University of Technology, Department of Materials and Environmental Technology, Ehitajate tee 5, 19086 Tallinn, Estonia (e-mail: niina.dulova@taltech.ee).

$$
\begin{aligned}
& \mathrm{Fe}^{2+}+\mathrm{H}_{2} \mathrm{O}_{2} \rightarrow \mathrm{Fe}^{3+}+\mathrm{HO}^{-}+\mathrm{HO}^{-} \\
& \mathrm{Fe}^{3+}+\mathrm{H}_{2} \mathrm{O}_{2} \rightarrow \mathrm{Fe}^{2+}+\mathrm{HO}_{2}^{-}+\mathrm{H}^{+}
\end{aligned}
$$

Recently, the innovative treatment technique based on the persulfate ( $\mathrm{PS}, \mathrm{S}_{2} \mathrm{O}_{8}{ }^{2-}$ ) oxidation has been studied as an alternative to $\mathrm{HO}^{-}$-AOTs for water matrices treatment [11]-[16]. The persulfate is a strong oxidant that after activation produce even stronger sulfate radical $\left(\mathrm{SO}_{4}{ }^{-}\right)$[13]. The main methods used for $\mathrm{SO}_{4}{ }^{-}$- generation are heat (Eq. (3)), UV or US irradiation (Eq. (4)) activation, transition metal ion (Eq. (5)) activation, alkaline activation, strong oxidant activation [13], [17].

$$
\begin{gathered}
\mathrm{S}_{2} \mathrm{O}_{8}{ }^{2-}+\text { heat } \rightarrow 2 \mathrm{SO}_{4}{ }^{-} \\
\mathrm{S}_{2} \mathrm{O}_{8}{ }^{2-}+\text { radiation } \rightarrow 2 \mathrm{SO}_{4}{ }^{--} \\
\mathrm{S}_{2} \mathrm{O}_{8}{ }^{2-}+\mathrm{M}^{\mathrm{n+}} \rightarrow \mathrm{M}^{(\mathrm{n}+1)+}+\mathrm{SO}_{4}{ }^{--}+\mathrm{SO}_{4}{ }^{2-}
\end{gathered}
$$

The oxidation by $\mathrm{SO}_{4}^{--}$has several advantages over $\mathrm{HO}^{-}$-AOTs. Namely, different from $\mathrm{HO}^{\circ}, \mathrm{SO}_{4}{ }^{-}$is more stable and selective for oxidizing unsaturated double and triple bonds as well as aromatic constituents [17]. Moreover, the $\mathrm{SO}_{4}{ }^{2-}$, which is the main product of PS decomposition, is innocuous for the environment. Therefore, the application of activated PS is usually suggested as a feasible selection for the advanced chemical oxidation of a wide range of contaminants. Furthermore, the structure of PS is a symmetrically substituted derivative of HP [18] and among different transition metals used in persulfate activation, $\mathrm{Fe}^{2+}$ is the most frequently applied metal. As a consequence, the oxidation by ferrous ion-activated PS has substantial degree of similarity with the $\mathrm{HP} / \mathrm{Fe}^{2+}$ system, and the efficacy of both processes could be simply compared. Notably, during the ferrous ion-activated HP or PS treatment of industrial effluents, the oxidation and coagulation of ferric oxyhydroxides both contribute to the removal of the organic load. Conversely, practical application of these AOTs could be limited because of the large amount of ferric sludge generated during coagulation step unless the complete reuse of ferric oxyhydroxide sludge as an iron source in the following Fenton-based treatment is undertaken [19].

Therefore, the main purpose of this study was to evaluate and compare the potential of the $\mathrm{HP} / \mathrm{Fe}^{2+}$ and $\mathrm{PS} / \mathrm{Fe}^{2+}$ process in organic load and selected target compounds removal from 
three different highly polluted industrial effluents: a paint production wastewater, phenolic wastewater, and mature landfill leachate. It was proposed, that the results obtained within this study could help to expand the knowledge of ferrous ion-activated hydrogen peroxide and persulfate applicability to treat real high-strength industrial effluents.

\section{MATERIALS AND METHODS}

\section{A. Chemicals and Materials}

Hydrogen peroxide (PERDROGENTM, $\geq 30 \%$ ), sodium persulfate $\left(\mathrm{Na}_{2} \mathrm{~S}_{2} \mathrm{O}_{8}, \geq 99 \%\right)$ and ferrous sulfate heptahydrate $\left(\mathrm{FeSO}_{4} \cdot 7 \mathrm{H}_{2} \mathrm{O}, \geq 99 \%\right)$ were purchased from Sigma-Aldrich. All of the other chemicals were of reagent grade and used without further purification. Ultrapure water (Millipore Simplicity ${ }^{\circledR}$ UV System) was used to prepare the stock solutions. Sulfuric acid $\left(\mathrm{H}_{2} \mathrm{SO}_{4}\right)$ and sodium hydroxide $(\mathrm{NaOH})$ aqueous solutions were used to adjust the $\mathrm{pH}$.

The studied real wastewater samples were comprised of: i) Sample 1 (S1) - a paint production wastewater consisting mainly of equipment wash water and residues of water-based multi-color paints, ii) Sample 2 (S2) - a phenolic wastewater formed during condensation of vapor from an oil shale thermal process, and iii) Sample 3 (S3) - a mature municipal landfill leachate. The collected effluents were stored at $4{ }^{\circ} \mathrm{C}$. The main properties of wastewater samples are presented in Table I.

\begin{tabular}{llll}
\multicolumn{4}{c}{ TABLE I: THE MAIN PARAMETERS OF STUDIED WASTEWATER SAMPLES } \\
\hline Parameter (unit) & S1 & S2 & S3 \\
\hline COD (g/L) & 42.3 & 40.1 & 9.8 \\
DOC (g/L) & 2.6 & 9 & 2.75 \\
BOD $_{7}(\mathrm{~g} / \mathrm{L})$ & 0.25 & 5.6 & 2.5 \\
$\mathrm{BOD}_{7} / \mathrm{COD}$ & 0.006 & 0.14 & 0.26 \\
TPC (g/L) & $\mathrm{n} / \mathrm{a}$ & 0.75 & 0.025 \\
$\mathrm{pH}$ & 7.75 & 8.9 & 7.85 \\
TSS (g/L) & 1.6 & $\mathrm{n} / \mathrm{a}$ & 3.4 \\
TS (g/L) & 66.7 & 0.45 & 14 \\
TFS (g/L) & 8 & 0.34 & 9.4 \\
\hline n/a - not analyzed & & &
\end{tabular}

\section{B. Experimental Procedure}

The coagulation with commercial ferric sulfate coagulant was performed in a jar test apparatus (Kemira). The sample $\mathrm{S} 1$ volume in each jar was $0.6 \mathrm{~L}$. The coagulant doses varied in the range of $100-1000 \mathrm{mgFe} / \mathrm{L}$. The operating conditions were as follows: $1 \mathrm{~min}$ of fast mixing at $400 \mathrm{rpm}, 30 \mathrm{~min}$ of slow mixing at $40 \mathrm{rpm}$, and $\sim 20 \mathrm{~h}$ of sedimentation.

All of the Fenton and $\mathrm{PS} / \mathrm{Fe}^{2+}$ treatment trials were performed in batch mode and in non-buffered solutions at ambient room temperature $\left(22 \pm 1^{\circ} \mathrm{C}\right)$. Effluent samples $(0.5$ $\mathrm{L})$ were treated in a $1 \mathrm{~L}$ cylindrical glass reactor with a constant agitation speed $(\sim 300 \mathrm{rpm})$ for a period of $24 \mathrm{~h}$. First, the activator $\left(\mathrm{FeSO}_{4} \cdot 7 \mathrm{H}_{2} \mathrm{O}\right)$ was added, and after its complete dissolution, the $\mathrm{HP} / \mathrm{Fe}^{2+}$ or $\mathrm{PS} / \mathrm{Fe}^{2+}$ oxidation was initiated by immediately adding oxidant. The initial $\mathrm{pH}\left(\mathrm{pH}_{0}\right)$ of the wastewater samples was adjusted to 3 in the subsequent treatment, unless otherwise specified. The oxidation was terminated by addition of $\mathrm{NaOH}(2$ or $10 \mathrm{M})$ to adjust the $\mathrm{pH}$ of the treated samples to $\sim 8$. This process was followed by a settling period of $\sim 20 \mathrm{~h}$. Finally, the supernatant was collected for further analysis. The wastewater oxidation experiments with non-activated HP and PS were conducted in identical reactors under the same treatment conditions for the respective activated oxidation trials.

All experiments were duplicated and the results of the analyses are presented as the mean with a standard deviation of at least three parallel replicates

\section{Analytical Methods}

The total solids (TS, $105{ }^{\circ} \mathrm{C}$ ), total suspended solids (TSS, $105{ }^{\circ} \mathrm{C}$ ), total fixed solids (TFS, $600{ }^{\circ} \mathrm{C}$ ), and the 7-day biochemical oxygen demand $\left(\mathrm{BOD}_{7}\right)$ were determined according to APHA [20]. The activated sludge used as a seed source in the $\mathrm{BOD}_{7}$ test was obtained from a municipal wastewater treatment plant in Tallinn, Estonia, and was not acclimated before $\mathrm{BOD}_{7}$ measurements. The chemical oxygen demand (COD) was determined using a closed reflux colorimetric method [20]. The correction for the hydrogen peroxide interference of the COD test was performed using the correlation equation reported by Kang et al. [21]. The $\mathrm{pH}$ was measured using a digital pH meter (Schott CG-840). The total iron concentration in the initial and treated samples was measured using an o-phenanthroline method [20]. The residual PS concentration in the treated samples was measured spectrophotometrically at $\lambda=352 \mathrm{~nm}$ by a potassium iodide reaction with PS towards the formation of $I_{2}$ [22]. The residual HP concentration in the treated samples was measured spectrophotometrically at $\lambda=410 \mathrm{~nm}$ with titanium sulfate by a hydrogen peroxide- $\mathrm{Ti}^{4+}$ complex formation [23]. The total phenolic content (TPC) was measured spectrophotometrically with aminoantipyrine according to ISO 6439 [24]. The dissolved organic carbon (DOC) was measured in filtered $(0.45 \mu \mathrm{m}, \mathrm{CA}$ membrane) wastewater samples using a TOC analyzer multi N/C® 3100 (Analytik Jena).

\section{RESUlTS AND DISCUSSION}

\section{A. Paint Manufacturing Wastewater Treatment}

Coagulation with ferric sulfate was utilized to remove suspended organic and inorganic compounds from the highly loaded S1 (Table I) and to provide a pre-treatment step before subsequent advanced chemical oxidation. As a result, 96 and $85 \%$ of COD and DOC, respectively, were removed from the S1 wastewater at a coagulant dosage of $200 \mathrm{mgFe} / \mathrm{L}$, mainly because of a considerable decrease in the TS ( $\geq 95 \%)$ and TSS $(\geq 50 \%$ ) concentration. Besides, more than a 10 -fold increase in a $\mathrm{BOD}_{7} / \mathrm{COD}$ ratio was observed in the pre-coagulated S1 (cS1), indicating effective bio-recalcitrant compounds removal during the coagulation step but still inadequate to ensure no inhibitory effect on the microbial activity of biomass. Therefore, the subsequent $\mathrm{HP} / \mathrm{Fe}^{2+}$ and $\mathrm{PS} / \mathrm{Fe}^{2+}$ experiments were conducted only with $\mathrm{cS} 1$ (COD = $1.17 \mathrm{~g} / \mathrm{L}, \mathrm{DOC}=0.300 \mathrm{~g} / \mathrm{L}$ ) and the data presented in Figs. 1 and 2 indicates a purification efficacy of the oxidation process only. 
The results of the Fenton treatment of $\mathrm{cS} 1$ at different COD/HP weight ratios after oxidation step $\left(\mathrm{pH}_{0} 3\right)$ and sedimentation phase $(\mathrm{pH} \sim 8)$ are shown in Fig. 1. The effect of HP concentration was studied for the Fenton treatment of $\mathrm{cS} 1$ at the fixed $\mathrm{HP} / \mathrm{Fe}^{2+}$ weight ratio of $5 / 1$, which is optimal for highly loaded wastewater treatment [8]. An increase in the applied Fenton reagent dose led to an improvement in wastewater treatment efficacy. Irrespective of $\mathrm{HP}$ concentration, the DOC removal was lower than COD reduction. It should be noted that at a $\mathrm{COD} / \mathrm{HP} / \mathrm{Fe}^{2+}$ weight ratio of $1 / 1 / 0.2$ the mineralization was twice less effective than COD removal. For higher oxidant doses (COD/HP/Fe ${ }^{2+}$ weight ratio of $1 / 2 / 0.4$ and $1 / 3 / 0.6$ ) the extent of DOC removal was more comparable with reduction in COD. In the Fenton treated $\mathrm{cS} 1$, irrespective of HP concentration used, no traces of residual oxidant were detected.

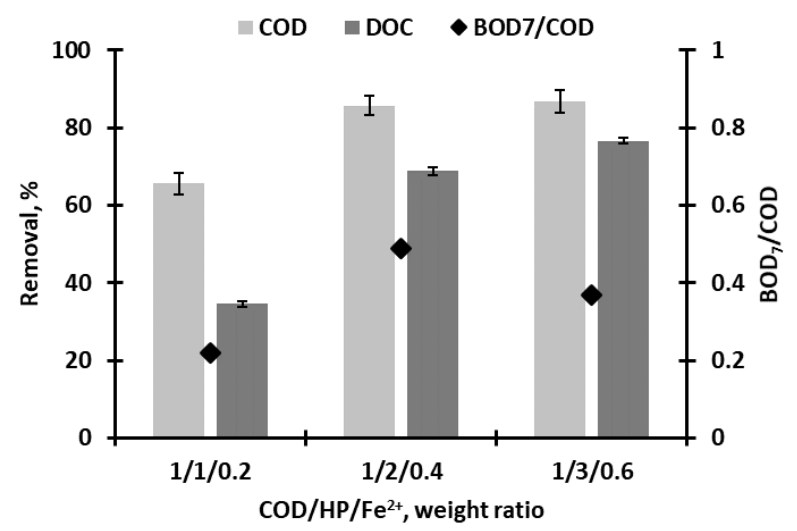

Fig. 1. $\mathrm{COD}$ and $\mathrm{DOC}$ removal and the $\mathrm{BOD}_{7} / \mathrm{COD}$ ratio as a function of the $\mathrm{COD} / \mathrm{HP} / \mathrm{Fe}^{2+}$ weight ratio in the $\mathrm{HP} / \mathrm{Fe}^{2+}$ treatment of $\mathrm{cS} 1$ wastewater.

The most effective $\mathrm{COD} / \mathrm{HP} / \mathrm{Fe}^{2+}$ weight ratio for the pre-coagulated $\mathrm{S} 1$ proved to be $1 / 2 / 0.4$ resulting in 14 and $31 \%$ of residual COD and DOC, respectively. Additionally, the $\mathrm{BOD}_{7} / \mathrm{COD}$ ratio increase was the highest at the same weight ratio and reached a final value of 0.49 , which means more than a 6-fold and 81-fold increase compared to the pre-coagulated and initial $\mathrm{S} 1$, respectively.

The oxidative potential of non-activated HP was studied as well. The results of the oxidation at a COD/HP weight ratio of $1 / 2$ indicated a negligible COD removal and more than $50 \%$ of unused HP in $\mathrm{cS} 1$ after $24 \mathrm{~h}$ of oxidation.

The ferrous ion-activated activated PS treatment experiments were also performed with a 24-h oxidation $\left(\mathrm{pH}_{0}\right.$ 3 ) and $\sim 20$-h sedimentation step $(\mathrm{pH} \sim 8)$ to ensure the complete dissociation of PS and to simplify the comparison of the studied systems. Accordingly, the COD removal remained nearly identical in trials with a $\mathrm{COD} / \mathrm{PS} / \mathrm{Fe}^{2+}$ weight ratio of 1/1/0.2, 1/2/0.4 and 1/3/0.6 and did not exceed $35 \%$ as presented in Fig. 2. The DOC removal was similar as well in all the ferrous ion-activated PS trials. In general, the mineralization was less effective than COD reduction and comprised no more than $7 \%$. The residual PS was detected in all treated cS1 samples, but comprised less than $10 \%$. Similar to the other studied parameters, the $\mathrm{BOD}_{7} / \mathrm{COD}$ ratio was steady after the $\mathrm{PS} / \mathrm{Fe}^{2+}$ treatment and nearly identical to the value obtained for the initial $\mathrm{cS} 1$.

The observed lower cS1 treatment efficacy by the PS/Fe $\mathrm{F}^{2+}$ process as compared to the Fenton treatment can be explained by the absence of simultaneous ferrous ions oxidation and ferric ions reduction in the $\mathrm{PS} / \mathrm{Fe}^{2+}$ system as presented in Eq. (2) for the Fenton process. The possible mechanism of PS ferrous ion activation may be described as follows [14]:

$$
\begin{aligned}
& \mathrm{Fe}^{2+}+\mathrm{S}_{2} \mathrm{O}_{8}{ }^{2-} \rightarrow \mathrm{Fe}^{3+}+\mathrm{SO}_{4}{ }^{--}+\mathrm{SO}_{4}{ }^{2-} \\
& \mathrm{SO}_{4}{ }^{--}+\mathrm{Fe}^{2+} \rightarrow \mathrm{Fe}^{3+}+\mathrm{SO}_{4}{ }^{2-}
\end{aligned}
$$

Accordingly, the reaction between PS and $\mathrm{Fe}^{2+}$ via Eq. (6) results in fast formation of $\mathrm{SO}_{4}{ }^{-}$. However, the $\mathrm{SO}_{4}{ }^{-}$also reacts with $\mathrm{Fe}^{2+}$ and rapidly converts it to $\mathrm{Fe}^{3+}$ through Eq. (7). Consequently, the oxidation of $\mathrm{Fe}^{2+}$ to $\mathrm{Fe}^{3+}$ occurs not only in the generation of $\mathrm{SO}_{4}{ }^{-}$, but also in the conversion of $\mathrm{SO}_{4}{ }^{--}$to $\mathrm{SO}_{4}{ }^{2-}$. The newly generated $\mathrm{SO}_{4}{ }^{-}$reacts immediately though the competitive reactions with organic pollutants and excess $\mathrm{Fe}^{2+}$ resulting in lower degradation efficiency of the organic contaminants. In order to control the reaction presented in Eq. (7), the adjustment of activator dose could be done. Accordingly, three different $\mathrm{COD} / \mathrm{PS} / \mathrm{Fe}^{2+}$ weight ratios of $1 / 1 / 0.1,1 / 1 / 0.2$, and $1 / 1 / 0.4$ were used to treat the pre-coagulated $\mathrm{S} 1$ as presented in Fig. 2. The increase in COD and DOC removal was negligible with increase in the activator concentration. On the other hand, the dissociation of persulfate proved dependent on activator dose, and thus the residual PS concentration comprised 10,7 , and $1 \%$ at a $\mathrm{COD} / \mathrm{PS} / \mathrm{Fe}^{2+}$ weight ratio of $1 / 1 / 0.1,1 / 1 / 0.2$, and $1 / 1 / 0.4$, respectively.

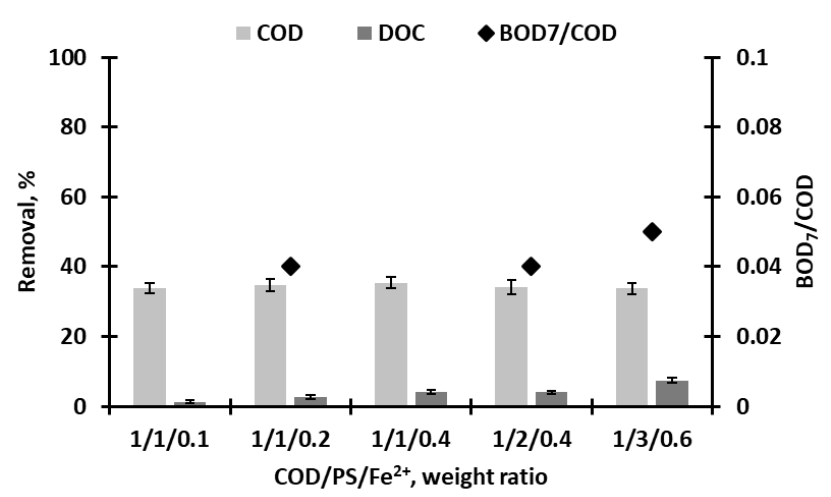

Fig. 2. $\mathrm{COD}$ and $\mathrm{DOC}$ removal and the $\mathrm{BOD}_{7} / \mathrm{COD}$ ratio as a function of the $\mathrm{COD} / \mathrm{PS} / \mathrm{Fe}^{2+}$ weight ratio in the $\mathrm{PS} / \mathrm{Fe}^{2+}$ treatment of $\mathrm{cS} 1$ wastewater.

The results of the non-activated PS treatment at a COD/PS weight ratio of $1 / 2$ indicated no changes in COD and DOC values and more than $93 \%$ of unused persulfate in cS1 after $24 \mathrm{~h}$ of oxidation.

In general, the application of the ferrous ion-activated PS process for the treatment of pre-coagulated paint production wastewater was less effective as compared to the Fenton process. The highest obtained overall COD and DOC removal was $99.5 / 96.5 \%$ and $98 / 89 \%$ for the pre-coagulation combined with $\mathrm{HP} / \mathrm{Fe}^{2+}$ and $\mathrm{PS} / \mathrm{Fe}^{2+}$ system, respectively.

\section{B. Phenolic Wastewater Treatment}

The results of $\mathrm{S} 2$ treatment by the Fenton system at different COD/HP/ $/ \mathrm{Fe}^{2+}$ weight ratios are presented in Fig. 3. Similar to the cS1 trials, the weight ratio of $\mathrm{HP} / \mathrm{Fe}^{2+}$ was 
maintained at 5/1. As it was expected, an increase in the applied oxidant concentration led to an enhancement in the organic load removal (COD, DOC) and biodegradability $\left(\mathrm{BOD}_{7} / \mathrm{COD}\right)$ of the treated $\mathrm{S} 2$ samples. In general, the mineralization was lower than the COD removal; e.g. at a $\mathrm{COD} / \mathrm{HP} / \mathrm{Fe}^{2+}$ weight ratio of $1 / 0.4 / 0.08$, the DOC removal was two times less effective $(29 \%)$ than the reduction in COD $(58 \%)$. No traces of residual HP were detected in the treated S2 samples, indicating the complete dissociation of oxidant under the studied treatment conditions. The non-activated HP oxidation at a COD/HP weight ratio of 1/0.4 resulted in negligible organic contaminants degradation and more than $85 \%$ of unused HP after $24 \mathrm{~h}$ of treatment.

In the case of Fenton treatment trials without $\mathrm{pH}_{0}$ adjustment, a fast drop in the $\mathrm{pH}$ of the reaction mixture was observed at the beginning of the oxidation most likely due to the acidity of the added Fenton reagents and the formation of acidic intermediates. Accordingly, the final $\mathrm{pH}\left(\mathrm{pH}_{\mathrm{f}}\right)$ values were lower than 2.7 in all the Fenton systems except for the treatment at a COD/HP/Fe ${ }^{2+}$ weight ratio of 1/0.4/0.08, which resulted in a $\mathrm{pH}_{\mathrm{f}}$ of 4.22. Notably, the adjustment of the $\mathrm{pH}_{0}$ to 3 prior to the addition of the reagents in the Fenton treatment at a $\mathrm{COD} / \mathrm{HP} / \mathrm{Fe}^{2+}$ weight ratio of $1 / 0.4 / 0.08$ resulted in COD and DOC removal enhancement up to 11 and $5 \%$, respectively.

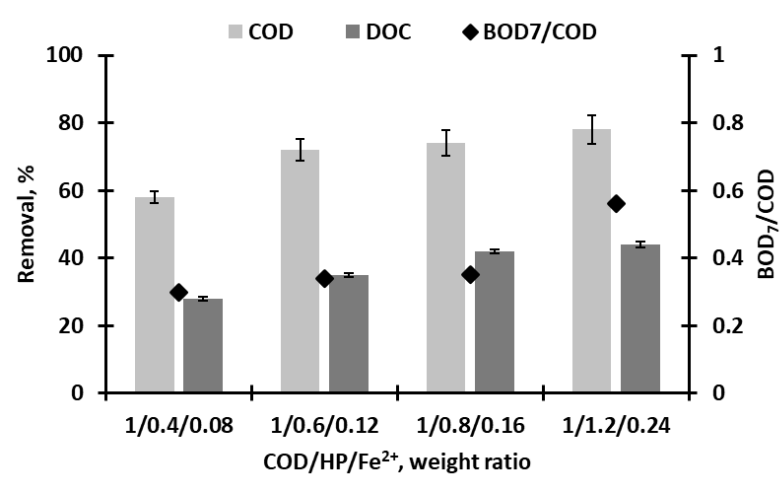

Fig. 3. $\mathrm{COD}$ and $\mathrm{DOC}$ removal and the $\mathrm{BOD}_{7} / \mathrm{COD}$ ratio as a function of the $\mathrm{COD} / \mathrm{HP} / \mathrm{Fe}^{2+}$ weight ratio in the $\mathrm{HP} / \mathrm{Fe}^{2+}$ treatment of $\mathrm{S} 2$ wastewater.

The temperature increase $(\mathrm{T} \uparrow)$ and excessive foam formation immediately after activation of hydrogen peroxide belong to the main challenges in the full-scale application of the Fenton process for industrial wastewater treatment. In the present study, a moderate $\mathrm{T} \uparrow$ of $10^{\circ} \mathrm{C}$ and foam formation of as much as $25 \%$ of the initial S2 sample volume were observed during treatment at a $\mathrm{COD} / \mathrm{HP} / \mathrm{Fe}^{2+}$ weight ratio of $1 / 0.4 / 0.08$. However, the application of Fenton oxidation at a $\mathrm{COD} / \mathrm{HP} / \mathrm{Fe}^{2+}$ weight ratio of $1 / 1.2 / 0.24$ resulted in a substantial $\mathrm{T} \uparrow$ of more than $50{ }^{\circ} \mathrm{C}$ and more aggressive foam formation as large as $300 \%$ of the initial sample volume. Accordingly, the addition of an anti-foaming agent as well as temperature monitoring may be required to control the foam production and exothermic reaction. To overcome these limitations, ferrous ion-activated persulfate was studied as an alternative process to treat the high-strength $\mathrm{S} 2$.

The application of $\mathrm{PS} / \mathrm{Fe}^{2+}$ system resulted in lower organic load removal and biodegradability improvement than the Fenton process (Figs. 3 and 4). On the other hand, only negligible $\mathrm{T} \uparrow\left(2-4{ }^{\circ} \mathrm{C}\right)$ and the complete exclusion of foam formation observed during the $\mathrm{PS} / \mathrm{Fe}^{2+}$ oxidation makes this advanced method a viable solution for the treatment of $\mathrm{S} 2$.

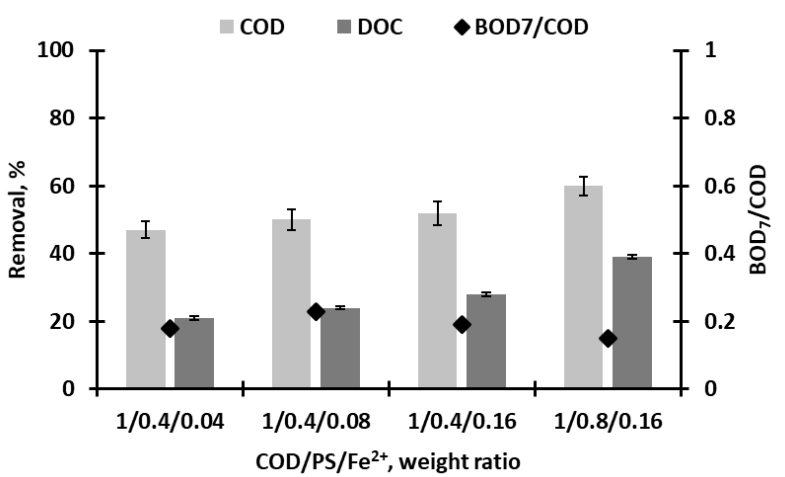

Fig. 4. $\mathrm{COD}$ and $\mathrm{DOC}$ removal and the $\mathrm{BOD}_{7} / \mathrm{COD}$ ratio as a function of the $\mathrm{COD} / \mathrm{PS} / \mathrm{Fe}^{2+}$ weight ratio in the $\mathrm{PS} / \mathrm{Fe}^{2+}$ treatment of $\mathrm{S} 2$ wastewater.

To assess the efficacy of the ferrous ion-activated persulfate oxidation, the effect of different oxidant and activator concentrations (Fig. 4) along with $\mathrm{pH}_{0}$ adjustment to 3 was studied. The COD and DOC removal remained nearly identical after treatment at the fixed COD/PS weight ratio of $1 / 0.4$ applying different $\mathrm{PS} / \mathrm{Fe}^{2+}$ weight ratios. Conversely, a 2-fold increase in the PS concentration up to a $\mathrm{COD} / \mathrm{PS} / \mathrm{Fe}^{2+}$ weight ratio of $1 / 0.8 / 0.16$ at the fixed $\mathrm{PS} / \mathrm{Fe}^{2+}$ weight ratio of $5 / 1$ resulted in an additional COD and DOC removal of 10 and $15 \%$, respectively.

The results of the non-activated persulfate treatment at a COD/PS weight ratio of $1 / 0.4$ resulted in considerable organic load elimination (COD and DOC removal comprised 47 and $11 \%$, respectively). The BOD7 reduction was similar in all of the trials, resulting in a lower BOD7/COD ratio after treatment at a COD/PS/ $\mathrm{Fe}^{2+}$ weight ratio of 1/0.8/0.16. Only traces of oxidant and more than $25 \%$ of undissociated PS were observed in the treated S2 samples after application of the ferrous ion-activated and non-activated persulfate, respectively. Similar to the $\mathrm{HP} / \mathrm{Fe}^{2+}$ experiments, a fast decrease in the $\mathrm{pH}$ of the reaction mixture was observed at the beginning of the persulfate oxidation without $\mathrm{pH}_{0}$ adjustment resulting in the $\mathrm{pH}_{\mathrm{f}}$ values lower than 2.4 in all of the systems. The regulation of the $\mathrm{pH}_{0}$ to $\sim 3$ applied to ensure presence of the $\mathrm{Fe}^{2+}$ at the beginning of the oxidation and thus to improve the treatment efficacy showed negligible improvement in the $\mathrm{COD}, \mathrm{DOC}$ and $\mathrm{BOD}_{7}$ removal.

Additionally, the efficacy of the studied AOTs in phenolic compounds degradation was evaluated. The results indicated that $\geq 90 \%$ decrease in TPC was attained both after the Fenton treatment and ferrous ion-activated PS process application.

\section{Municipal Landfill Leachate Treatment}

In the case of $\mathrm{S} 3$ trials, the oxidant dose was determined as the COD/PS or COD/HP molar ratio. The HP/Fe ${ }^{2+}$ molar ratio of 10/1 was considered optimal [8]; for comparison, the $\mathrm{PS} / \mathrm{Fe}^{2+}$ molar ratio was also fixed at $10 / 1$. In both ferrous ion-activated systems the $\mathrm{pH}_{0}$ was adjusted to 3 in order to provide activator in its reduced state and also to facilitate the comparison of considered AOTs.

As presented in Fig. 5, the removal of organic load proved dependent on the applied Fenton reagent dose. The COD and DOC removal was improved along with the oxidant 
concentration increase in $\mathrm{COD} / \mathrm{HP} / \mathrm{Fe}^{2+}$ molar ratio from $1 / 0.1 / 0.01$ to $1 / 1 / 0.1$ resulting in 65.5 and $60 \%$, respectively. Notably, the dissociation of HP was complete in all the studied Fenton systems. Regarding the efficacy of phenolic compounds removal, the application of Fenton process at a $\mathrm{COD} / \mathrm{HP} / \mathrm{Fe}^{2+}$ molar ratio of $1 / 0.1 / 0.01$ resulted in $60 \%$ decrease in TPC concentration; further increase of oxidant dose up to a $\mathrm{COD} / \mathrm{HP} / \mathrm{Fe}^{2+}$ molar ratio of $1 / 0.25 / 0.025$ resulted in degradation of $90 \%$ of phenolic substances. The results of the non-activated oxidation of $\mathrm{S} 3$ at a $\mathrm{COD} / \mathrm{HP}$ molar ratio of $1 / 1$ resulted in negligible organic load removal after $24 \mathrm{~h}$ of treatment

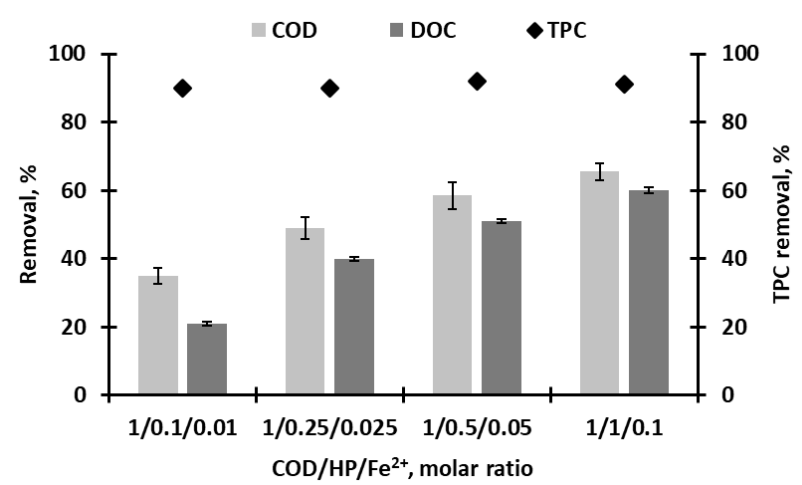

Fig. 5. COD, DOC and TPC removal as a function of the $\mathrm{COD} / \mathrm{HP} / \mathrm{Fe}^{2+}$ molar ratio in the $\mathrm{HP} / \mathrm{Fe}^{2+}$ treatment of $\mathrm{S} 3$ wastewater.

The effect of different oxidant doses on the efficacy of the $\mathrm{PS} / \mathrm{Fe}^{2+}$ treatment at the fixed $\mathrm{PS} / \mathrm{Fe}^{2+}$ molar ratio of $10 / 1$ is shown in Fig. 6. The results indicated steady improvement in COD, DOC, and TPC removal with the PS concentration increasing in COD/PS/ $\mathrm{Fe}^{2+}$ molar ratio from 1/0.1/0.01 to $1 / 1 / 0.1$. Accordingly, a 10 -fold oxidant dose increase in $\mathrm{COD} / \mathrm{PS} / \mathrm{Fe}^{2+}$ molar ratio from $1 / 0.1 / 0.01$ to $1 / 1 / 0.1$ resulted in enhancement of COD removal form $19 \%$ to $36.5 \%$, respectively. Similarly, the mineralization extent was the highest at a COD/PS/ $\mathrm{Fe}^{2+}$ molar ratio of 1/1/0.1 reaching $36 \%$.

The non-activated PS oxidation at a COD/PS molar ratio of $1 / 0.25$ and $1 / 0.5$ resulted in $6-11 \%$ of COD and $3-10 \%$ of DOC removal after 24-h treatment of S3 samples. Therefore, the activation of PS proved essential to facilitate the removal of total organic load and degradation of specific phenolic compounds during municipal landfill leachate treatment.

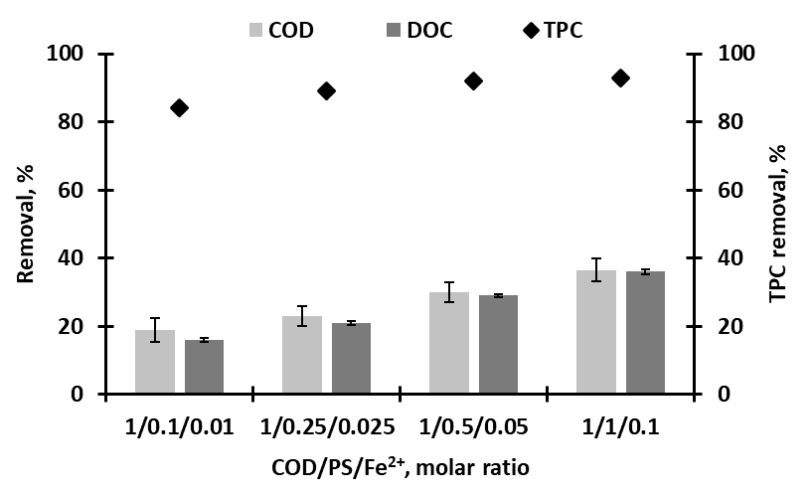

Fig. 6. COD, DOC and TPC removal as a function of the COD/PS/Fe ${ }^{2+}$ molar ratio in the $\mathrm{PS} / \mathrm{Fe}^{2+}$ treatment of $\mathrm{S} 3$ wastewater.

The changes in temperature and foam formation were also measured during S3 treatment by the $\mathrm{PS} / \mathrm{Fe}^{2+}$ and $\mathrm{HP} / \mathrm{Fe}^{2+}$. The results of the Fenton treatment at a $\mathrm{COD} / \mathrm{HP} / \mathrm{Fe}^{2+}$ molar ratio of $1 / 1 / 0.1$ indicated a moderate $\mathrm{T} \uparrow$ of $12{ }^{\circ} \mathrm{C}$. In contrast the application of ferrous ion-activated PS process at the same oxidant concentration proved to have negligible exothermic effect. Furthermore, the production of excessive foam caused by the $\mathrm{CO}_{2}$ and $\mathrm{O}_{2}$ evolution as a result of $\mathrm{HP}$ decomposition was observed in the $\mathrm{HP} / \mathrm{Fe}^{2+}$ systems.

Comparison of the obtained results suggests that the $\mathrm{HP} / \mathrm{Fe}^{2+}$ process is more efficient for organic load removal from landfill leachate. On the other hand, the $\mathrm{PS} / \mathrm{Fe}^{2+}$ process proved to have no restrictions by temperature rise or excessive foam formation.

\section{CONCLUSIONS}

The results of this study demonstrate that both the $\mathrm{HP} / \mathrm{Fe}^{2+}$ and $\mathrm{PS} / \mathrm{Fe}^{2+}$ systems are promising treatment techniques to reduce the organic load, degrade persistent organic pollutants and improve the biodegradability in different highly contaminated industrial effluents. Generally, the application of the Fenton process demonstrated a higher treatment efficacy than the $\mathrm{PS} / \mathrm{Fe}^{2+}$ system for all the studied wastewater samples. On the contrary, the $\mathrm{HP} / \mathrm{Fe}^{2+}$ oxidation was characterized by a temperature increase and excessive foam formation. Thus, the ferrous ion-activated PS process could be suggested as a practical alternative technique due to the reasonable working conditions and sustainable treatment of the effluents. The application of the studied AOTs proved to be an effective option that improved the overall wastewater quality and increased the possibility of subsequent biological treatment of the effluents. The results of this study are unique and may provide important insight for further implementation in treatment of heavily contaminated water matrices.

\section{CONFLICT OF INTEREST}

The authors declare no conflict of interest.

\section{AUTHOR CONTRIBUTIONS}

ND and EK planned experiments. EK conducted laboratory experiments and samples analysis. ND interpreted the results and wrote the paper. MT provided critical feedback on the research and paper writing. All authors approved the final version.

\section{ACKNOWLEDGMENT}

The financial support provided by the Institutional Development Program of TUT for 2016-2022, project 2014-2020.4.01.16-0032, from EU Regional Development Fund and the Estonian Research Council grant PRG776 are gratefully acknowledged.

\section{REFERENCES}

[1] M. Liu, S. Preis, I. Kornev, Y. Hu, and C.-H. Wei, "Pulsed corona discharge for improving treatability of coking wastewater," J. Environ. Sci., vol. 64, pp. 306-316, 2018.

[2] R. C. Martins, A. M. T. Silva, S. Castro-Silva, P. Garção-Nunes, and R. M. Quinta-Ferreira, "Advanced oxidation processes for treatment of 
effluents from a detergent industry," Environ. Technol., vol. 32, pp. 1031-1041, 2011.

[3] D. B. Miklos, C. Remy, M. Jekel, K. G. Linden, J. E. Drewes, and U. Hübner, "Evaluation of advanced oxidation processes for water and wastewater treatment - A critical review," Water Res., vol. 139, pp. 118-131, 2018

[4] I. Oller, S. Malato, and J. A. Sánchez-Pérez, "Combination of Advanced Oxidation Processes and biological treatments for wastewater decontamination - A review," Sci. Total Environ., vol. 409, pp. 4141-4166, 2011.

[5] L. Onga, I. Kornev, and S. Preis, "Oxidation of reactive azo-dyes with pulsed corona discharge: Surface reaction enhancement," vol. 103, article 103420, 2020

[6] D. E. Santiago, J. Araña, O. González-Díaz, E. Henríquez-Cárdenes, J. A. Ortega-Méndez, E. Pulido-Melián, J. M. Doña-Rodríguez, and J. Pérez-Peña, "Treatment of wastewater containing imazalil by means of Fenton-based processes," Desalin. Water Treat., vol. 57, pp. 13865-13877, 2016.

[7] J. L. Wang and L. J. Xu, "Advanced oxidation processes for wastewater treatment: Formation of hydroxyl radical and application," Crit. Rev. Environ. Sci. Technol., vol. 42, pp. 251-325, 2012.

[8] P. Bautista, A. F. Mohedano, J. A. Casas, J. A. Zazo, and J. J. Rodriguez, "An overview of the application of Fenton oxidation to industrial wastewaters treatment," J. Chem. Technol. Biotechnol., vol. 83, pp. 1323-1338, 2008.

[9] L. Chu, J. Wang, J. Dong, H. Liu, and X. Sun, "Treatment of coking wastewater by an advanced Fenton oxidation process using iron powder and hydrogen peroxide," Chemosphere, vol. 86, pp. 409-414, 2012.

[10] N. Dulova and M. Trapido, "Application of Fenton's Reaction for Food-processing Wastewater Treatment," J. Adv. Oxid. Technol., vol. 14, pp. 9-16, 2011.

[11] Y. Ji, W. Xie, Y. Fan, Y. Shi, D. Kong, and J. Lu, "Degradation of trimethoprim by thermo-activated persulfate oxidation: Reaction kinetics and transformation mechanisms," Chem. Eng. J., vol. 286, pp. 16-24, 2016.

[12] H. Lebik-Elhadi, Z. Frontistis, H. Ait-Amar, F. Madjene, D. Mantzavinos, "Degradation of pesticide thiamethoxam by heat activated and ultrasound-activated persulfate: Effect of key operating parameters and the water matrix," Proc. Safe. Environ. Prot., vol. 134, pp. 197-207, 2020

[13] L. W. Matzek and K. E. Carter, "Activated persulfate for organic chemical degradation: A review," Chemosphere, vol. 151, pp. 178-188, 2016.

[14] M. A. Moussa and C. Serge, "Solar photo-Fenton like using persulphate for carbamazepine removal from domestic wastewater," Water Res., vol. 48, pp. 229-236, 2014.

[15] J. Wang, and S. Wang, "Activation of persulfate (PS) and peroxymonosulfate (PMS) and application for the degradation of emerging contaminants," Chem. Eng. J., vol. 334, pp. 1502-1517, 2018.

[16] B.-T. Zhang, Y. Zhang, Y. Teng, and M. Fan, "Sulfate radical and its application in decontamination technologies," Crit. Rev. Environ. Sci. Technol., vol. 45, pp. 1756-1800, 2015.

[17] S. Wacławek, H. V. Lutze, K. Grübel, V. V. T. Padil, M. Černík, and D. D. Dionysiou, "Chemistry of persulfates in water and wastewater treatment: A review," Chem. Eng. J., vol. 330, pp. 44-62, 2017.
[18] C. Liang, C. J. Bruell, M. C. Marley, and K. L. Sperry, "Persulfate oxidation for in situ remediation of TCE. I. Activated by ferrous ion with and without a persulfate-thiosulfate redox couple," Chemosphere, vol. 55, pp. 1213-1223, 2004.

[19] E. Kattel, M. Trapido, and N. Dulova, "Treatment of landfill leachate by continuously reused ferric oxyhydroxide sludge-activated hydrogen peroxide," Chem. Eng. J., vol. 304, pp. 646-654, 2016.

[20] APHA (American Public Health Association), Standard Methods for the Examination of Water and Wastewater $23^{\text {rd }}$ edn, American Water Works Association, Water Environment Federation, Washington DC, USA, 2017.

[21] Y. W. Kang, M.-J. Cho, and K.-Y. Hwang, "Correction of hydrogen peroxide interference on standard chemical oxygen demand test," Water Res., vol. 33, pp. 1247-1251, 1999.

[22] C. Liang, C.-F. Huang, N. Mohanty, and R. M. Kurakalva, "A rapid spectrophotometric determination of persulfate anion in ISCO," Chemosphere, vol. 73, pp. 1540-1543, 2008.

[23] G. M. Eisenberg, "Colorimetric determination of hydrogen peroxide," Ind. Eng. Chem. Anal. Ed., vol. 15, pp. 327-328, 1943.

[24] ISO 6439, Water Quality - Determination of Phenol Index 4-Aminoantipyrine Spectrometric Methods after Distillation, Geneva, Switzerland, International Organization for Standardization, 1990.

Copyright $\odot 2020$ by the authors. This is an open access article distributed under the Creative Commons Attribution License which permits unrestricted use, distribution, and reproduction in any medium, provided the original work is properly cited ( $\underline{\text { C BY } 4.0)}$.

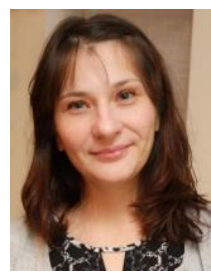

Niina Dulova was graduated from Tallinn University of Technology (TalTech) in 2004 with a MSc degree and defended her doctoral degree in environmental engineering at TalTech in 2008. She has worked at TalTech since 2003, first as a research assistant, engineer and researcher, and since 2008 as a senior researcher. Her main research areas are related to environmental engineering and technology studies involving the application of advance oxidation technologies for hazardous compounds contaminated water/wastewater treatment and soil remediation.

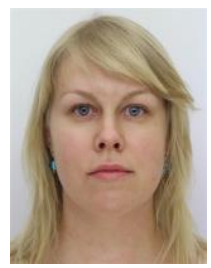

Eneliis Kattel was graduated from TalTech in 2013 with a MSc degree and in 2018 with a doctoral degree in environmental engineering. She has worked at TalTech since 2013, first as an engineer and research staff, and since 2018 as a researcher. Her main research areas are related to environmental technology, including the application of advanced oxidation technologies for the purification of contaminated water matrices.

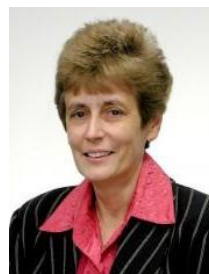

Marina Trapido was graduated from TalTech in 1974 as a Chemical Engineer (cum laude). She received a Doctoral degree from N.N. Petrov Research Institute of Oncology in 1986. She has worked at TalTech since 2002, first as a senior researcher and associate professor, and since 2011 as a full professor. Her main areas of research are bio- and environmental sciences, environmental monitoring and environmental technology, including advanced oxidation technologies. 